\begin{tabular}{|l|l|}
\hline JURNAL ABDI MASYA & $\begin{array}{l}\text { Volume 1 Nomor 1 } \\
\text { November 2020 } \\
\text { pp 15-20 } \\
\text { E-ISSN : dalam proses } \\
\text { P-ISSN : dalam proses }\end{array}$ \\
\hline
\end{tabular}

\title{
PELATIHAN PENGENDALIAN, PROTEKSI DAN PEMELIHARAAN MOTOR LISTRIK BAGI GURU, TOOLMAN SERTA SISWA SMK JURUSAN TEKNIK PEMESINAN
}

\section{ELECTRIC MOTOR CONTROL, PROTECTION AND MAINTENANCE TRAINING FOR TEACHERS, TOOLMAN AND VOCATIONAL SCHOOL STUDENTS DEPARTMENT OF MECHANICAL ENGINEERING}

\author{
Petrus Heru Sudargo ${ }^{\left.1^{*}\right)}$, Kaleb Priyanto ${ }^{2)}$, Bambang Margono ${ }^{3)}$ \\ 1) ,2), 3)Program Studi Teknik Mesin, Sekolah Tinggi Teknologi Warga Surakarta \\ *Email : petrus@sttw.ac.id
}

\begin{abstract}
ABSTRAK
Pelatihan ketrampilan mengenai pengendalian, proteksi dan pemeliharaan motor listrik dimaksudkan untuk memberi ketrampilan bagi siswa SMK, guru, dan toolman (tenaga kependidikan bagian bengkel) dalam melakukan pemasangan maupun perbaikan instalasi listrik secara mandiri selain itu juga memiliki pengetahuan dan ketrampilan mengenai pengendalian, proteksi dan pemeliharaan motor listrik. Dengan demikian siswa SMK, guru, dan toolman mempunyai pengetahuan untuk instalasi listrik yang aman sehingga peluang terjadi kesalahan bisa dihindarkan. Pelatihan ini diberikan dalam dua tahap, yaitu tahap pembekalan materi dan tahap pengujian materi, baik secara teori maupun praktek. Dengan pelatihan ini diharapkan peserta memahami dengan baik tentang bahaya listrik dan cara mengamankannya, membaca gambar instalasi, mengukur tegangan, mendeteksi sambungan yang putus, dan dapat membuat instalasi memiliki pengetahuan dan ketrampilan mengenai pengendalian, proteksi dan pemeliharaan motor listrik. Tingkat keberhasilan peserta diukur dari nilai ujian secara teori maupun praktek, dengan standar nilai minimum 70. Pelatihan ini diikuti oleh 20 siswa SMK, guru, dan toolman yang sebagian besar tidak memiliki pengalaman tentang instalasi listrik. Secara umum pelatihan ini diharapkan dapat meningkatkan ketrampilan siswa SMK, guru, dan toolman. Selain bermanfaat bagi peserta, peralatan pasca pelatihan yang diserahkan oleh tim laboratorium instalasi listrik STT"Warga" Surakarta dapat digunakan untuk membekali dan memberikan kegiatan yang bermanfaat bagi masyarakat di wilayahnya dan tim laboratorium instalasi listrik STT "Warga" Surakarta dapat mengelola pelatihan instalasi listrik tegangan rendah secara mandiri dan berkelanjutan.
\end{abstract}

Kata-kata kunci: SMK, pelatihan instalasi listrik, Motor listrik

\section{Submit : 09 Agustus 2020, Accepted: 15 Oktober 2020 Published : 24 November 2020}

\section{PENDAHULUAN}

Gerak putar motor listrik sudah sejak lama dimanfaatkan untuk mendukung pekerjaan manusia. Motor listrik adalah perangkat elektromagnetik yang menghasilkan gerak mekanik. Gerak mekanik tersebut digunakan untuk menghasilkan gerak putar pada peralatan seperti impeller pompa, fan atau blower, menggerakkan kompresor, mengangkat bahan material berat dan lain-lain. Motor listrik digunakan juga untuk kebutuhan harian rumah tangga seperti pada mixer, mesin cuci, dan kipas angin. (Pedoman Efisiensi Energi untuk Industri di Asia. [1].

Kontrol motor listrik mempunyai peran penting dalam dunia industri modern saat ini. Seiring perkembangan kemajuan ilmu pengetahuan dan teknologi, sistem kontrol motor telah mendorong manusia 
untuk berusaha mengatasi segala permasalahan yang timbul di sekitarnya dengan cara yang lebih mudah, efisien dan efektif. Jenis motor listrik yang paling banyak digunakan adalah motor induksi. Salah satu aplikasi motor induksi di industri adalah untuk menggerakkan konveyor. Kelancaran akan sistem produksi di industri sangat ditentukan oleh kinerja dari motor induksi. Maka untuk menjamin kinerja motor induksi maka harus ada dukungan perencanaan instalasi tenaga listrik yang matang [2][3].

Instalasi tenaga listrik merupakan hal yang harus diperhatikan dalam rangka pemanfaatan energi listrik untuk berbagai macam keperluan rumah tangga dan usaha dengan tetap memperhatikan aspek keselamatan penggunanya. Instalasi listrik harus memenuhi 5 prinsip dasar yaitu keamanan, keandalan, kemudahan tercapai, ketersediaan, dan ekonomis [4]. Prinsip dasar instalasi listrik yang paling utama adalah keamanan (safety) yang ditujukan untuk manusia, peralatan, dan lingkungan. Setiap orang yang menggunakan dan bekerja pada bidang listrik harus memperhatikan hal-hal yang berkaitan dengan keamanan terutama terhadap arus kejut. Jika terjadi kontak dengan tegangan, aliran arus akan melalui tubuh dan menghasilkan kejutan listrik yang meyebabkan tubuh kita terbakar dan luka serius, bahkan dapat menyebabkan kematian [5][6]. Kematian akibat arus listrik menduduki urutan ke empat (9\%) dengan penyebab utama adalah kesalahan pemasangan instalasi listrik di industri. National Safety Council (lembaga safety nasional di Amerika) memperkirakan 600 orang meninggal akibat arus listrik. Banyak kecelakaan terjadi pada sistem tegangan di bawah 600 Volt [7].

Kurikulum SMK khususnya jurusan teknik pemesinan membekali siswa untuk dapat mengoperasikan berbagai jenis mesin perkakas. Perawatan dan pemeliharaan mesin bukan menjadi fokus utama capaian pembelajaran yang disampaikan. Namun seringkali lulusan SMK jurusan teknik pemesinan tidak selalu bekerja sebagai operator mesin saja. Banyak dari mereka dituntut harus memahami prinsip kerja mesin, kontrol, dan pemeliharaannya. Salah satu bagian utama mesin perkakas yang menjadi kuda kerjanya adalah motor. Seorang teknisi di industri harus memahami bagaimana instalasi listrik untuk mendukung kinerja motor yang benar, bagaimana sistem kontrolnya, bagaimana sistem proteksinya, terlebih pemeliharaannya sehingga motor dapat bekerja pada kondisi yang selalu optimal. Durasi penggunaan yang panjang dan beban yang besar tidak menutup kemungkinan berakibat kendala pada motor [6][7]. Hal tersebut terlebih terjadi pada motor yang tidak memperoleh pemeliharaan rutin dan penanganan kerusakan sejak dini. Sehingga pemahaman dan ketrampilan mengenai Pengendalian, Proteksi dan Pemeliharaan Motor Listrik perlu dimiliki oleh setiap siswa khususnya jurusan teknik pemesinan

\section{METODE}

Alat dan bahan yang digunakan:

a. Kabel NYA 2,5 mm dan $1,5 \mathrm{~mm}$

b. Tang potong

c. Tang kombinasi

d. Tang lancip

e. Isolasi

f. Last dop

Metode yang digunakan dalam pengabdian ini adalah sebagai berikut:

a. Ceramah singkat: untuk penyuluhan sejumlah informasi dibantu dengan modul yang berisi materi pelatihan.

b. Tanya jawab: dapat dilakukan selama proses penyuluhan dan pelatihan, atau setelah proses tersebut.

c. Demonstrasi dan latihan: untuk memperlihatkan langkah kerja setiap materi yang diberikan, dan memperkenalkan alat simulasi sinyal listrik dari tubuh manusia, alat penghemat daya 
listrik, dan alat-alat ukur listrik. Peserta akan dibagi dalam 3-4 kelompok dengan bimbingan dosen-dosen.

d. Evaluasi: dilakukan melalui observasi langsung saat peserta beraktifitas selama pelatihan dan setelahnya. Dengan demikian dapat diketahui apakah ada peningkatan pengetahuan dan ketrampilan dalam menerapkan persyaratan pengukuran dan perhitungan daya listrik dan biayanya.

e. Pelaporan dan Keberlanjutan: Sebagai wujud akuntabilitas dan transparansi baik dalam pengelolaan keuangan dan administrasi maka pelaporan segera dilakukan disertai bukti fisiknya. Hasil evaluasi kegiatan menjadi proyeksi untuk keberlanjutan program dalam bentuk pendampingan.

Kegiatan ini memberi kesempatan peserta pelatihan akan berlatih teknikteknik penyambungan antara 2 penghantar (kabel) seperti rangkaian pada Gambar 1.Teknik penyambungan tersebut antara lain dengan cara ekor babi (pig tail), puntir, bolak balik (turnback), sambungan kabel bernadi banyak, cabang datar (plain joint) dan cabang simpul (knotted tap joint). Penyambungan haruslah dipasang dengan rapat dan benar sesuai dengan syarat-syarat dalam Persyaratan Umum Instalasi Listrik [3].

Peserta pelatihan berjumlah 24 pemuda yang berasal dari organisasi karang taruna kelurahan Karangasem Surakarta. Pendidikan tertinggi peserta adalah tingkat SMK dan SMA dengan rata-rata usia 16 dan 17 tahun. Antusiaisme peserta tercermin dari kehadiran yang tinggi dari permintaan 21 peserta menjadi 24 peserta. Dilihat dari tingkat pengetahuan tentang instalasi listrik, hanya 8 orang yang mempunyai pengalaman memasang instalasi listrik karena memiliki pengetahuan kejuruan, selebihnya tidak memiliki pengetahuan tentang hal tersebut dan belum pernah memasangnya.

Tingkat keberhasilan peserta diukur dari nilai ujian praktek selama pelatihan dengan mengacu pada Tabel 1. Peserta dinyatakan berhasil bila memperoleh nilai minimum 70. Dari hasil penilaian selama kegiatan berlangsung, maka $75 \%$ peserta berhasil memperoleh nilai sebesar 70 atau lebih, sedangkan sisanya memperoleh nilai kurang dari 70 dikarenakan tingkat pemahaman yang rendah.

Gambar 1,2 dan 3 menampilkan proses pelatihan yang dimulai dari koordinasi dengan laboran teknik instalasi listrik STT "Warga" Surakarta mengenai hal-hal yang berkaitan dengan kegiatan pelatihan. Kemudian dilakukan pembelian peralatan praktek instalasi penerangan dan alat tulis kantor untuk peserta. Pelaksanaan pelatihan dimulai dari pembekalan secara teoritis materi instalasi listrik dilanjutkan dengan praktik instalasi penerangan. Selesai pelatihan peserta dibekali buku petunjuk dan satu set peralatan penunjang agar mereka dapat melakukan pemasangan atau perbaikan instalasi secara mandiri. Pihak mitra dibekali 21 set peralatan instalasi penerangan agar dapat digunakan di kemudian hari oleh peserta atau warga daerah asalnya.

\section{HASIL DAN DISKUSI}

Peserta pelatihan berjumlah 20 pemuda yang berasal dari organisasi karang taruna kelurahan Karangasem Surakarta. Pendidikan tertinggi peserta adalah tingkat SMK dan SMA dengan rerata usia 16 dan 17 tahun. Antusiaisme peserta tercermin dari kehadiran yang tinggi dari permintaan 21 peserta menjadi 24 peserta. Dilihat dari tingkat pengetahuan tentang instalasi listrik, hanya 8 orang yang mempunyai pengalaman memasang instalasi listrik karena memiliki pengetahuan kejuruan, selebihnya tidak memiliki pengetahuan tentang hal tersebut dan belum pernah memasangnya. 
Tabel 1. Acuan keberhasilan pelatihan

\begin{tabular}{lcc}
\hline \multicolumn{1}{c}{ Kegiatan } & \multicolumn{2}{c}{ Tingkat Pemahaman } \\
\cline { 2 - 3 } & Selatihan Instalasi & Sesudah (\%) \\
\hline $\begin{array}{l}\text { Listrik rumah tinggal } \\
\text { a. Memahami teknologi instalasi }\end{array}$ & 0 & 70 \\
listrik & 0 & 70 \\
b. Membaca gambar & & \\
Instalasi listrik & 0 & 70 \\
c. Menggunakan alat ukur listrik & & 70 \\
sederhana & 0 & \\
d. Memasang instalasi listrik & & 70 \\
Pengujian & & 70 \\
Keterampilan & 0 & \\
a. Mengecek kondisi instalasi listrik & 0 & \\
b. Memperbaiki instalasi listrik & & \\
\hline
\end{tabular}

Tingkat keberhasilan peserta diukur dari nilai ujian praktek selama pelatihan dengan mengacu pada Tabel 1. Peserta dinyatakan berhasil bila memperoleh nilai minimum 80. Dari hasil penilaian selama kegiatan berlangsung, maka $75 \%$ peserta berhasil memperoleh nilai sebesar 80 atau lebih, sedangkan sisanya memperoleh nilai kurang dari 70 dikarenakan tingkat pemahaman yang rendah.

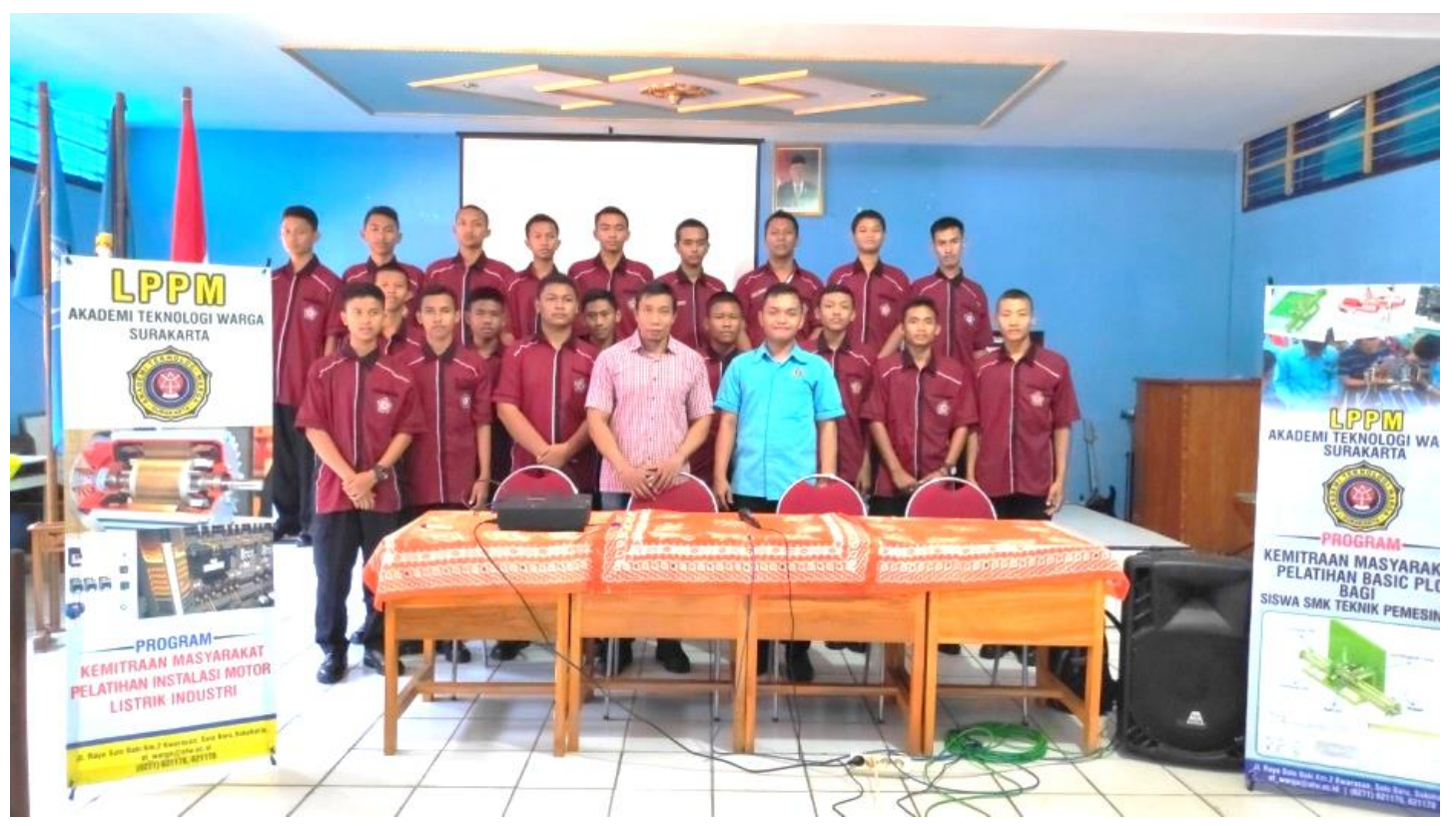

Gambar 1. Pembukaan Kegiatan oleh Bpk. Petrus Heru Sudargo, S.T., M.T. 


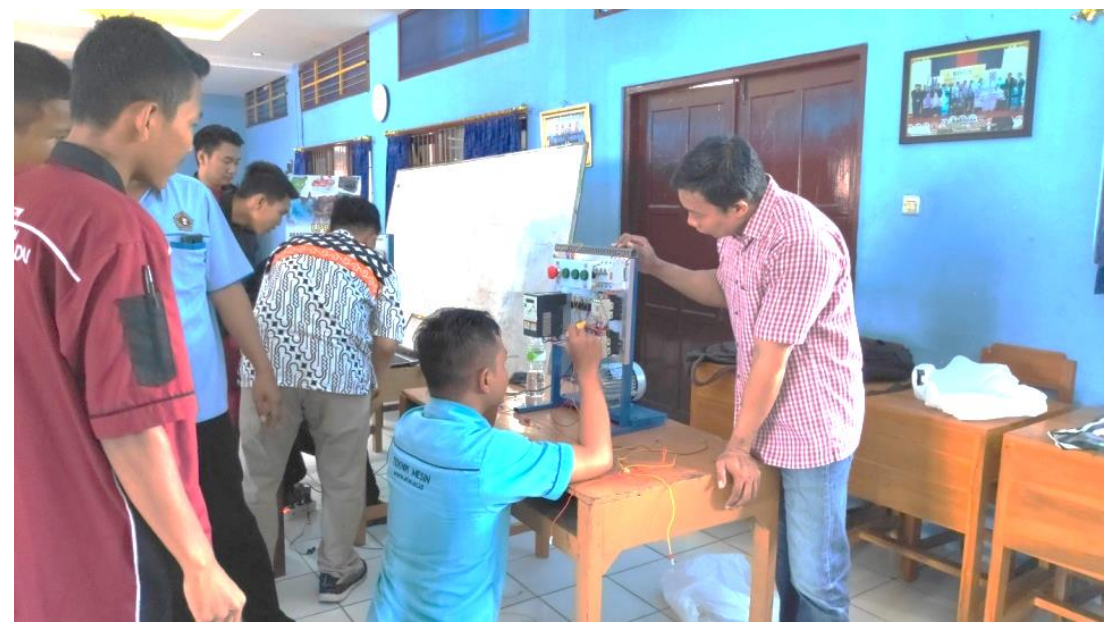

Gambar 2. Materi Rangkaian Dasar Kelistrikan dan melibatkan mahasiswa

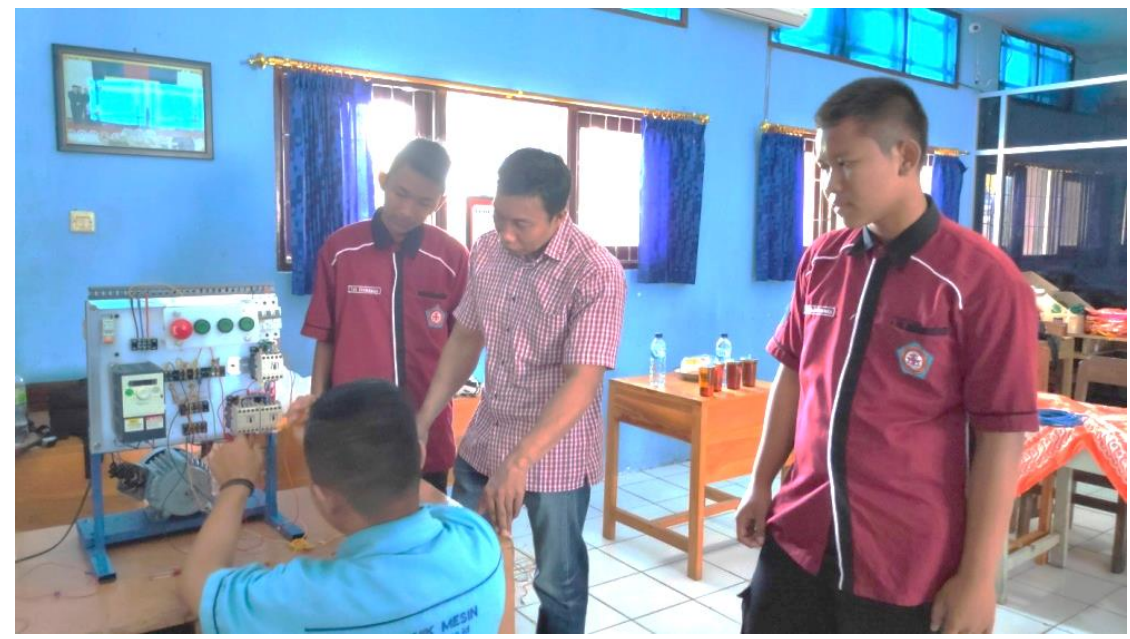

Gambar 3. Proses Praktek dasar rangkaian dan melibatkan mahasiswa

Gambar 1 sampai 3. menggambarkan proses pelatihan yang dimulai dari koordinasi dengan laboran teknik instalasi listrik STTW mengenai hal- hal yang berkaitan dengan kegiatan pelatihan. Kemudian dilakukan pembelian peralatan praktek instalasi penerangan dan ATK untuk peserta. Pelaksanaan pelatihan dimulai dari pembekalan secara teoritis materi instalasi listrik dilanjutkan dengan praktik instalasi penerangan. Selesai pelatihan peserta dibekali buku petunjuk dan satu set peralatan penunjang agar mereka dapat melakukan pemasangan atau perbaikan instalasi secara mandiri. Pihak mitra dibekali 10 set peralatan instalasi penerangan agar dapat digunakan di kemudian hari oleh peserta atau warga daerah asalnya.

\section{KESIMPULAN}

Apabila ingin menjadi teknisi instalasi listrik yang standar, dibutuhkan pengetahuan dan keterampilan yang memadai, karena ketidak terampilan dari seseorang yang terjun dalam bidang instalasi listrik akan mengakibatkan pekerja dan instalasi yang dibuat menjadi tidak aman dan andal. Hasil dari pelatihan ini adalah peserta memahami dengan baik tentang bahaya listrik dan cara mengamankannya, membaca gambar instalasi dan menggambarkan instalasi penerangan, dapat mengukur tegangan dan 
mendeteksi sambungan yang putus serta dapat membuat instalasi penerangan menggunakan berbagai macam saklar dan stop kontak.

\section{UCAPAN TERIMA KASIH}

Penulis mengucapkan terima kasih kepada Pusat Penelitian, Pengabdian Masyarakat Akademi Teknologi Warga Surakarta yang telah memberi dukungan terhadap keberhasilan pengabdian ini.

\section{DAFTAR PUSTAKA}

[1] www.energyefficiencyasia.org

[2] Indra., Z, dan Kamil, I., 2011,Analisis Sistem Instalasi Listrik Rumah Tinggal dan Gedunguntuk Mencegah Bahaya Kebakaran,Jurnal Ilmiah Elite Elektro, Vol. 2, No. 1, Maret 2011: 40-44

[3] Fanal, Circuit Practices, Mbh, 2001. Gunter G.Seip, Electrical Installation Hand book, Siemens, 2000.

[4] Standar Nasional Indonesia, Persyaratan Umum Instalasi Listrik (PUIL) 2000, SNI 04-0225-2000, Jakarta, 2000.

[5] Priowirjanto, Gator. "Instalasi Listrik Dasar." Jakarta: Erlangga, 2003.

[6] Harten, P.V. \& Setiawan, E. 1985, Instalasi Listrik Arus Kuat 2, Bina Cipta, Bandung PUIL, Pedoman Umum Instalasi Listrik, Jakarta, 2000.

[7] National Safety Council (NSC) US, (2012).

[8] Joewono, A., dan Tim AbdimasJurusan Teknik Elektro, Penyuluhan dan PelatihanKelistrikan Di Rumah Tangga,Universitas Katolik Widya Mandala Surabaya, 2014.

[9] Rifai, A., Buku Pintar Mengatasi Listrik di Rumah,Gema Buku Nusantara, Bandung, 2014. 